\title{
Six new species of the genus Caccothryptus from the Himalayas (Coleoptera: Limnichidae)
}

\author{
Keita MATSUMOTO \\ Department of Life Sciences, Natural History Museum, London, SW7 5BD, UK. \\ Email: k.matsumoto@nhm.ac.uk \\ (1) https://orcid.org/0000-0002-0527-7418 \\ urn:lsid:zoobank.org:author:EE9F7B89-8F83-4C8D-A89E-911DA7518B78
}

\begin{abstract}
Six new species of the genus Caccothryptus (Coleoptera: Limnichidae) are described from the Himalayan region: C. brendelli sp. nov., C. arakawae sp. nov., C. championi sp. nov., C. larryi sp. nov., C. tardarsauceae sp. nov. and C. abboti sp. nov. Photographs of type specimens with relevant morphological characters to distinguish species are provided.
\end{abstract}

Keywords. Limnichidae, taxonomy, Caccothryptus, new species, Himalayas.

Matsumoto K. 2021. Six new species of the genus Caccothryptus from the Himalayas (Coleoptera: Limnichidae). European Journal of Taxonomy 739: 168-184. https://doi.org/10.5852/ejt.2021.739.1275

\section{Introduction}

There are 28 currently described species of Caccothryptus Sharp, 1902. These species are distributed from the Palearctic region to the Oriental region (Spangler et al. 2001; Yoshitomi 2015, 2018; Hernando \& Ribera 2014, 2017). The genus was revised by Hernando \& Ribera (2014), and within that paper five species groups were proposed: compactus, rouyeri, testudo, jaechi and zetteli groups. Since that revision, eight new species have been described (Yoshitomi 2015, 2018; Hernando \& Ribera 2017).

Six new species described in this paper are from the Himalayan region and within the testudo and the compactus groups. Photographs of habitus and genitalia of Caccothryptus brendelli sp. nov., C. arakawae sp. nov., C. championi sp. nov., C. larryi sp. nov., C. tardarsauceae sp. nov. and C. abboti sp. nov. are provided with differential diagnosis.

\section{Material and methods}

All specimens used in this study are housed in the collection of the Natural History Museum, London $(\mathrm{BMNH})$. The specimens were examined by relaxing them in warm water, then dissecting the abdomen and its inner contents. Genitalia are mounted on a card pinned under the specimen. Habitus photographs were taken with a Canon DSLR camera, using a Laowa $25 \mathrm{~mm}$ macro lens. All photographs were processed through focus stacking software, Helicon Focus and were later edited using GIMP. The beginning and end of label text are indicated using double quotes (" "); a double slash (//) separates the data on different labels. 


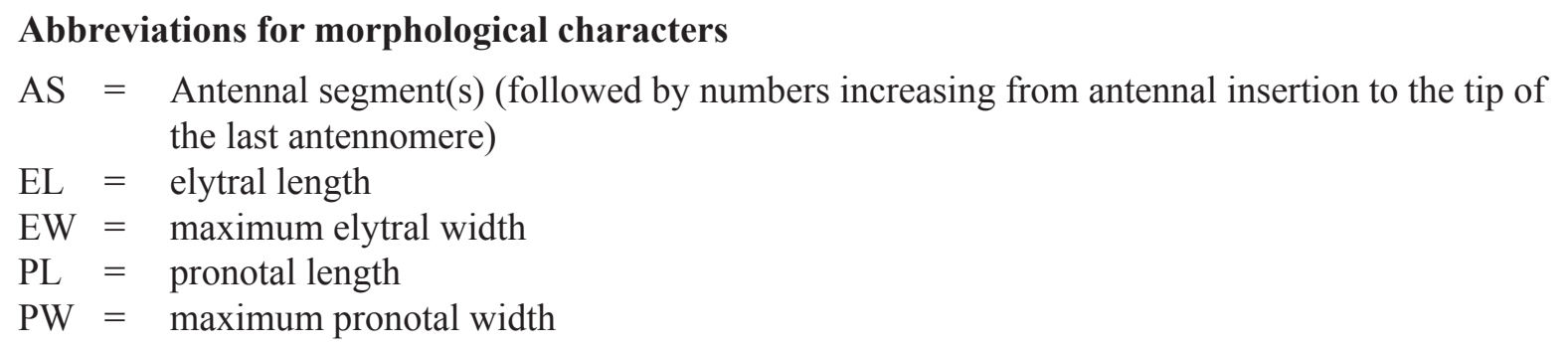

\title{
Results
}

\section{Taxonomy}

\author{
Class Insecta Linnaeus, 1758 \\ Order Coleoptera Linnaeus, 1758 \\ Suborder Polyphaga Emery, 1886 \\ Series Elateriformia Crowson, 1960 \\ Superfamily Byrrhoidea Latreille, 1804 \\ Family Limnichidae Erichson, 1846 \\ Genus Caccothryptus Sharp, 1902 \\ Caccothryptus brendelli sp. nov. \\ urn:lsid:zoobank.org:act:F29031E6-E8C9-4235-A03F-A483EA581FD2 \\ Figs 1, 7A
}

\section{Diagnosis}

Caccothryptus brendelli sp. nov. is within C. testudo group and can be distinguished by several genital characters: (1) apex of median lobe narrow with tip slightly pointed in ventral view; (2) concave structure between apical emargination narrowly V-shaped with rounded end; (3) dorsal side of parameres bisinuate in lateral view; (4) apical emargination of parameres $\mathrm{V}$-shaped in ventral view.

\section{Etymology}

This species is named after Martin J.D. Brendell, who was the curator of the Coleoptera Department of Entomology at the Natural History Museum, London.

\section{Material examined}

\section{Holotype}

NEPAL • đ̃; "NEPAL 5600' Kathmandu Dist. Godawari 25/v/1983 // UNDER BARK OF DEAD TREE // M.J.D.Brendell BMNH(E) 1983-222 // NHMUK011225276"; BMNH.

\section{Description}

\section{Male}

Body. Elongate, oval, dorsum convex, EL: $3.36 \mathrm{~mm}$, EW: $2.44 \mathrm{~mm}$, PL: $0.94 \mathrm{~mm}$, PW: $2.07 \mathrm{~mm}$. Colour: dorsal side brown; venter brown, tibia reddish brown, tarsal claws light brown. Dorsal surface densely covered with long setae with patches of white setae forming a wavy pattern, ventral surface with relatively long setae.

Dorsum. Head: partially retracted into pronotum; overall surface smooth, densely punctured across surface. Antennae: 11 segmented, filiform, fully pubescent, antennomeres long and slender, $1^{\text {st }}$ AS widest, $2^{\text {nd }}$ AS narrow and long, $3^{\text {rd }}$ AS smallest, $4^{\text {th }}-11^{\text {th }}$ AS long, thin and obtusely angled on one side. Pronotum: transverse, widest at posterior end, narrowest at anterior end, narrower than elytra; 
anterior margin convex, posterior margin trisinuate, lateral margin convex; surface covered with dense punctation, surface between punctures smooth and shiny. Scutellum: subtriangular, large, lateral sides nearly straight. Elytra: longer than wide; anterior margin slightly convex, sinuate; anterior lateral angle nearly right angled, pointed; lateral margins strongly bordered; surface with mixtures of small fine and medium sized punctuations; surface between punctures smooth and shiny.

VENTER. Prosternum: concave on anterior margin, outer lateral margin concave; prosternal process as long as wide, lateral margin sinuated, posterior margin rounded. Mesoventrite: wider than long, narrowed towards posterior; anterior end concave where prosternal process fits, discrimen visible; laterally subparallel and gently curved, posteriorly flat, anteriorly trisinuate. Metaventrite: long and wide, flat on the middle; discrimen thin visible across each end. Abdomen: five clearly visible ventrites. Intercoxal process with pointed apex. Posterior margin of $1^{\text {st }}$ and $2^{\text {nd }}$ ventrites convex, $3^{\text {rd }}-4^{\text {th }}$ ventrites slightly concave around the middle, $5^{\text {th }}$ ventrite curved. Surface covered with long, light yellow, recumbent setae.

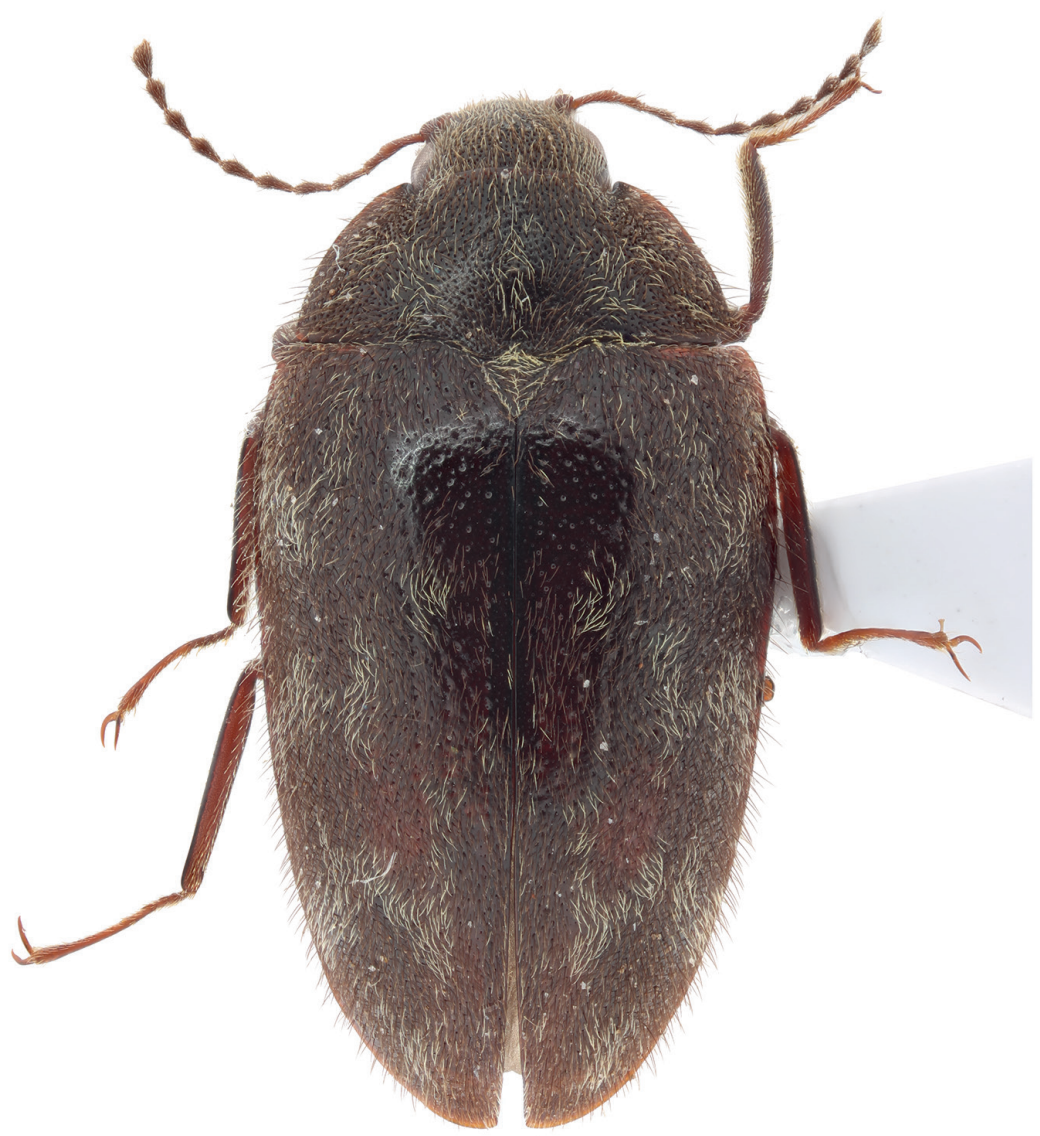

A

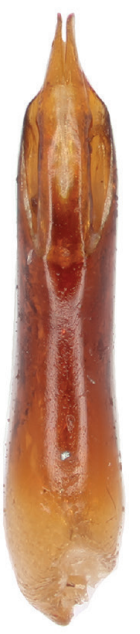

B

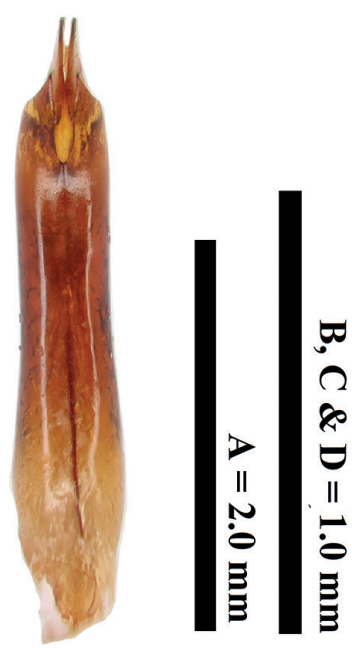

D

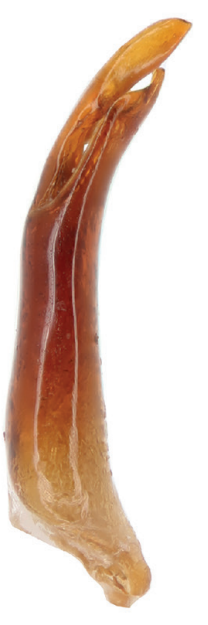

C
(1)

Fig. 1. Caccothryptus brendelli sp. nov., đo, holotype (NHMUK011225276). A. Dorsal habitus. B. Genitalia, dorsal. C. Genitalia, lateral. D. Genitalia, ventral. 
Legs. Tibia: protibia with outer and inner lateral ends curved. Meso- and metatibia with outer lateral margin almost straight, inner lateral margin straight. Tarsi: simple, segments increase in length towards the apex, $5^{\text {th }}$ tarsal segment as long as $1^{\text {st }}-4^{\text {th }}$ tarsal segment combined. Tarsal claws: long, narrow, symmetrical.

Genitalia. Aedeagus: elongate, strongly sclerotised. Base: asymmetrical, widest around basal 0.2 from both lateral and ventral view. Median lobe: approximately $2 / 5$ length of genitalia; longer than parameres; gently curved on dorsal side, bisinuate on ventral side, widest at near apical end, narrowing towards apex, apex with round point in lateral view; apex flat split into two on anterior half and edge pointed, lower half of lateral end relatively straight in dorsal view; triangular emarginate on one side towards the parameres and small emarginate directing laterally in ventral view. Parameres: wider than median lobe in ventral view; apical emargination V-shaped, concave structure between parameres elongated narrow and deeply V-shaped with rounded end; bisinuate, lower half of sinuation long and shallow, upper half short and slightly deep on dorsal side in lateral view; gently curved on ventral side in lateral view; apex rounded and not overlapping median lobe, majority of parameres not overlapping median lobe with two spaces visible in lateral view.

\section{Female}

Unknown.

\section{Distribution}

Caccothryptus brendelli sp. nov. is known only from the type locality.

Caccothryptus arakawae sp. nov. urn:1sid:zoobank.org:act:FB863BA1-2C04-435A-869C-5C6A16C82964

Figs 2, 7B

\section{Diagnosis}

Caccothryptus arakawae sp. nov. is within the C. testudo group and can be distinguished by several genital characters: (1) apex of median lobe narrows with tip slightly pointed in ventral view; (2) concave structure between apical emargination narrow U-shaped with rounded end; (3) dorsal side of parameres bisinuate in lateral view; (4) apical emargination of parameres V-shaped in ventral view.

\section{Etymology}

This species is named after Hiromi Arakawa, who is a Japanese manga artist.

\section{Material examined}

\section{Holotype}

NEPAL • ${ }^{7}$; "NEPAL: 5600' Kathmandu Dist., Godawari, 24.v.-6.vi.1983. // M.J.D.Brendell BMNH(E) 1983-222 // At light // NHMUK011225268"; BMNH.

\section{Paratypes}

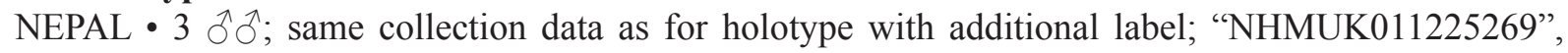
"NHMUK011225270", "NHMUK011225271"; BMNH • 2 क $\%$; same collection data as for holotype with additional label; "NHMUK011225272", "NHMUK011225273”; BMNH. 


\section{Description}

\section{Male}

Body. Elongate, oval, dorsum convex, EL: $3.39 \mathrm{~mm}$, EW: $2.36 \mathrm{~mm}$, PL: $0.93 \mathrm{~mm}$, PW: $2.03 \mathrm{~mm}$. Colour: dorsal side brown; venter brown, tibia reddish brown, tarsal claws light brown. Dorsal surface densely covered with long setae with patches of white setae forming a wavy pattern, ventral surface with relatively long setae.
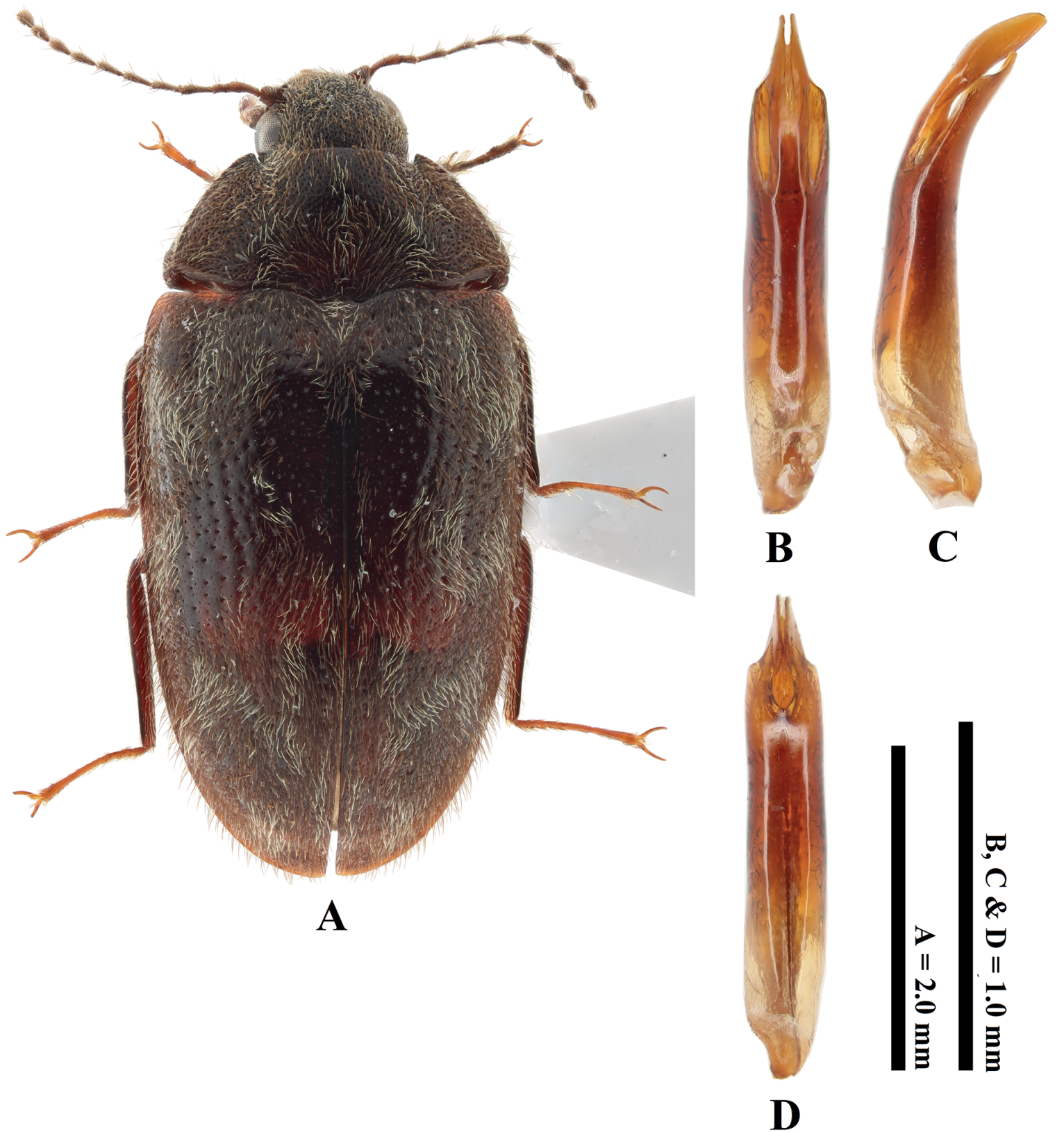

Fig. 2. Caccothryptus arakawae sp. nov., ô, holotype (NHMUK011225268). A. Dorsal habitus. B. Genitalia, dorsal. C. Genitalia, lateral. D. Genitalia, ventral. 
Dorsum. Head: partially retracted into pronotum; overall surface smooth, densely punctured across surface. Antennae: 11 segmented, filiform, fully pubescent, antennomeres long and slender, $1^{\text {st }}$ AS widest, $2^{\text {nd }}$ AS narrow and long, $3^{\text {rd }}$ AS smallest, $4^{\text {th }}-11^{\text {th }}$ AS long, thin and obtusely angled on one side. Pronotum: transverse, widest at posterior end, narrowest at anterior end, narrower than elytra; anterior margin convex, posterior margin trisinuate, lateral margin convex; surface covered with dense punctation, surface between punctures smooth and shiny. Scutellum: subtriangular, large, lateral sides nearly straight. Elytra: Longer than wide; anterior margin slightly convex, sinuate; anterior lateral angle nearly right angled, rounded; lateral margins strongly bordered; surface with mixtures of small fine and medium sized punctuations; surface between punctures smooth and shiny.

VENTER. Prosternum: concave on anterior margin, outer lateral margin concave; prosternal process as long as wide, lateral margin sinuated, posterior margin rounded. Mesoventrite: wider than long, narrowed towards posterior; anterior end concave where prosternal process fits, discrimen visible; laterally subparallel and gently curved, posteriorly flat, anteriorly trisinuate. Metaventrite: long and wide, flat on middle; discrimen not clearly visible. Abdomen: five clearly visible ventrites. Intercoxal process with pointed apex. Posterior margin of $1^{\text {st }}$ and $2^{\text {nd }}$ ventrites convex, $3^{\text {rd }}-4^{\text {th }}$ ventrites slightly concave around middle, $5^{\text {th }}$ ventrite curved. Surface covered with long, light yellow, recumbent setae.

LEGS. Tibia: protibia with outer and inner lateral ends curved. Meso- and metatibia with outer lateral margin almost straight, inner lateral margin straight. Tarsi: simple, segments increase in length towards apex, $5^{\text {th }}$ tarsal segment as long as $1^{\text {st }}-4^{\text {th }}$ tarsal segment combined. Tarsal claws: long, narrow, symmetrical.

Genitalia. Aedeagus: elongate, strongly sclerotised. Base: asymmetrical, widest around basal 0.2 from lateral, relatively consistent width in ventral view. Median lobe: approximately $2 / 5$ length of genitalia; longer than parameres; slightly bisinuate on dorsal side, bisinuate on ventral side, widest at near apical end, narrowing towards the apex, apex rounded in lateral view; apex flat split into two on anterior half and edge pointed, lower half of lateral end relatively straight in dorsal view; lower half narrows, upper half oval and tip slightly rounded in lateral view; apical end smooth and narrows inwards in ventral view. Parameres: wider than median lobe in ventral view; apical emargination V-shaped, concave structure between parameres elongated slightly narrow and deep U-shape with rounded end; bisinuate, lower half of sinuation long and shallow, upper half short and slightly deep on dorsal side in lateral view; gently curved on ventral side in lateral view; apex rounded and ever so slightly overlapping with median lobe, majority of parameres do not overlap median lobe with two spaces visible in lateral view.

\section{Female}

No morphological difference from male except for the longer $5^{\text {th }}$ abdominal ventrite. Ovipositor long, gonocoxites strongly tapering to a point.

\section{Morphological variation}

EL: 3.68-3.39 mm, EW: 2.52-2.35 mm, PL: 1.00-0.90 mm, PW: 2.11-2.03 mm.

\section{Distribution}

Caccothryptus arakawae sp. nov. is known only from the type locality. 
Caccothryptus championi sp. nov.

urn:lsid:zoobank.org:act:DADDC62C-E4BF-479F-89B8-9E057724D7CC

Figs 3, 7C

\section{Diagnosis}

Caccothryptus championi sp. nov. is within C. testudo group and can be distinguished by several genital characters: (1) apex of median lobe oval in ventral view; (2) concave structure between parameres an elongated narrow and deeply V-shaped with pointed end; (3) dorsal side of parameres narrowed gradually towards apical end, small bump near the apex in lateral view; (4) apical emargination of parameres V-shaped in ventral view.

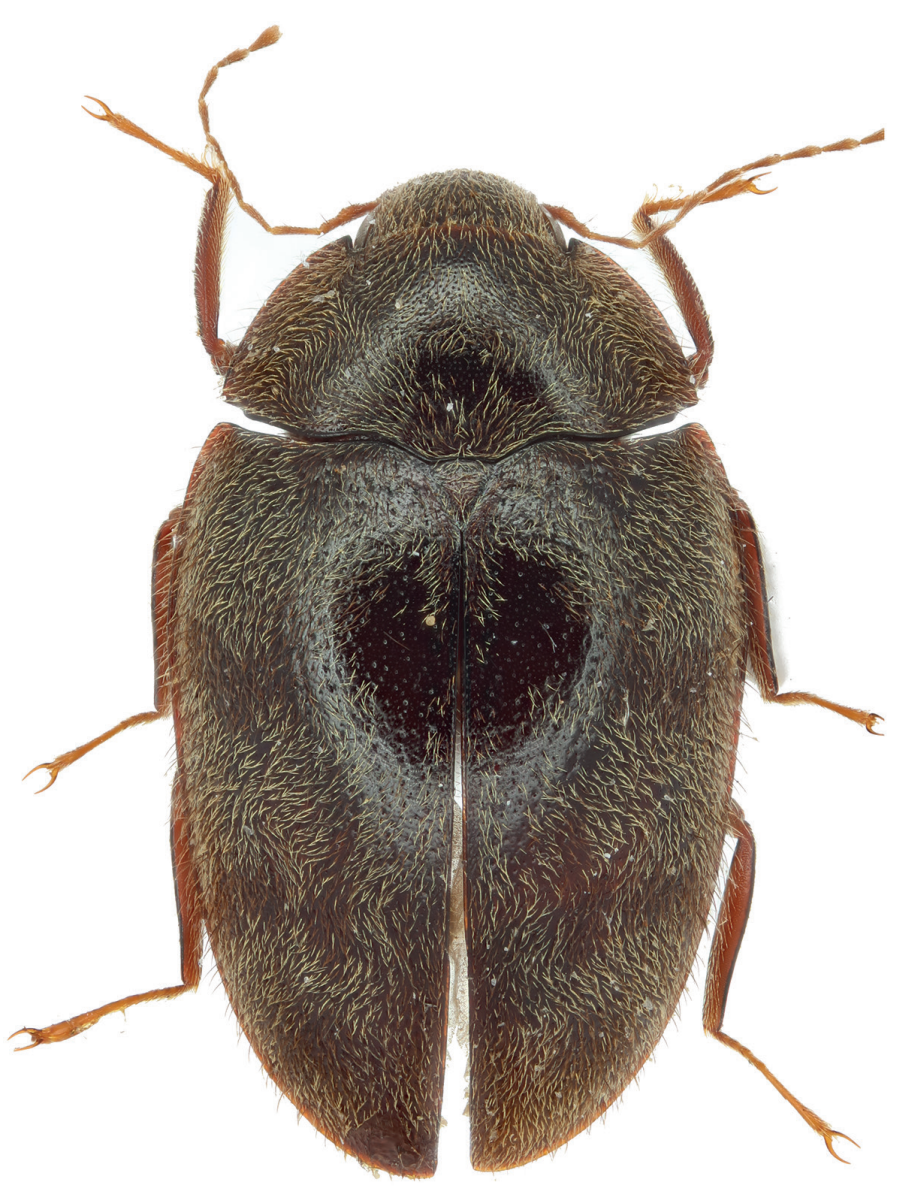

A
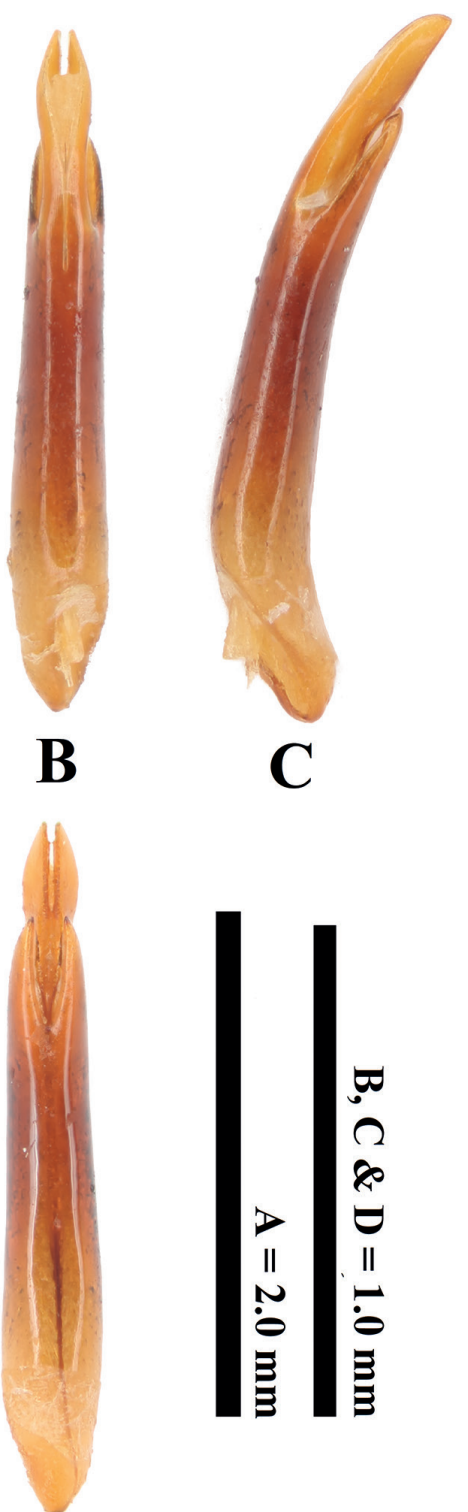

D

Fig. 3. Caccothryptus championi sp. nov., $\widehat{\jmath}$, holotype (NHMUK011225382). A. Dorsal habitus. B. Genitalia, dorsal. C. Genitalia, lateral. D. Genitalia, ventral. 


\section{Etymology}

This species is named after Harry George Champion, who collected this species.

\section{Material examined}

\section{Holotype}

INDIA • ô; "Haldwani, Dist., Kumaon, India: H.G.C. // H.G. Champion B.M. 1953-156 // NHMUK011225382”; BMNH.

\section{Paratypes}

INDIA - 18 specs; same collection data as for holotype, with additional label: "NHMUK011225383", "NHMUK011225384", "NHMUK011225385", "NHMUK011225386", "NHMUK011225388", "NHMUK011225436", "NHMUK011225441", "NHMUK011225442", "NHMUK011225443", "NHMUK011225444", "NHMUK011225492", "NHMUK011225494", "NHMUK011225495", "NHMUK011225496", "NHMUK011225497", "NHMUK011225498", "NHMUK011225499", "NHMUK011225500; BMNH • 6 specs; "Haldwani, Dist., Kumaon, India: H.G.C. H.G. Champion B.M. 1953-156" // [with additional label] "NHMUK011225387", "NHMUK011225437", "NHMUK011225438", "NHMUK011225439", "NHMUK011225440”, "NHMUK011225493”; BMNH - 2 specs; "Haldwani, Dist., Kumaon, India: H.G.C. // G.C. Champion B.M. 1926-146. // E. M. M. 1925. Det. G.C.C. Cacc. ripicola Ch" // [with additional label] "NHMUK011225548”, "NHMUK011225549"; BMNH.

\section{Description}

\section{Male}

Body. Elongate, oval, dorsum convex, EL: $3.33 \mathrm{~mm}$, EW: $2.47 \mathrm{~mm}$, PL: $0.93 \mathrm{~mm}$, PW: $2.06 \mathrm{~mm}$. Colour: dorsal side brown; venter brown, tibia reddish brown, tarsal claws light brown. Dorsal surface densely covered with long setae with patches of white setae forming a wavy pattern, ventral surface with relatively long setae.

Dorsum. Head: partially retracted into pronotum; overall surface smooth, densely punctured across surface. Antennae: 11 segmented, filiform, fully pubescent, antennomeres long and slender, $1^{\text {st }}$ AS widest, $2^{\text {nd }}$ AS narrow and long, $3^{\text {rd }}$ AS smallest, $4^{\text {th }}-11^{\text {th }}$ AS long, thin and obtusely angled on one side. Pronotum: transverse, widest at posterior end, narrowest at anterior end, narrower than elytra; anterior margin convex, posterior margin trisinuate, lateral margin convex; surface covered with dense punctation, surface between punctures smooth and shiny. Scutellum: subtriangular, large, lateral sides nearly straight. Elytra: longer than wide; anterior margin slightly convex, sinuate; anterior lateral angle nearly right angled, pointed; lateral margins strongly bordered; surface with mixtures of small fine and medium sized punctuations; elytral striae more clearly visible towards lateral end; surface between punctures smooth and shiny.

VENTER. Prosternum: concave on anterior margin, outer lateral margin concave; prosternal process as long as wide, lateral margin sinuated, posterior margin rounded. Mesoventrite: wider than long, narrowed towards posterior; anterior end concave where prosternal process fits, discrimen visible; laterally subparallel and gently curved, posteriorly flat, anteriorly trisinuate. Metaventrite: long and wide, flat on the middle; discrimen thin visible across each end. Abdomen: five clearly visible ventrites. Intercoxal process with pointed apex. Posterior margin of $1^{\text {st }}$ and $2^{\text {nd }}$ ventrites convex, $3^{\text {rd }}-4^{\text {th }}$ ventrites slightly concave around the middle, $5^{\text {th }}$ ventrite semioval. Surface covered with long, light yellow, recumbent setae.

Legs. Tibia: protibia with outer and inner lateral ends curved. Meso- and metatibia with outer lateral margin almost straight, inner lateral margin straight. Tarsi: simple, segments increase in length towards 
the apex, $5^{\text {th }}$ tarsal segment as long as $1^{\text {st }}-4^{\text {th }}$ tarsal segment combined. Tarsal claws: long, narrow, symmetrical.

GeNitALIA. Aedeagus: elongate, strongly sclerotised. Base: asymmetrical, widest around basal 0.2 from both lateral and ventral view. Median lobe: approximately $1 / 3$ length of genitalia; longer than parameres; gently curved on dorsal side, slightly bisinuate on ventral side, widest at middle, narrowing towards the apex, apex with round point in lateral view; apex pointed, split into two on anterior half and edge blunt, lower half of lateral end gently concave in dorsal view; apical end oval in ventral view. Parameres: wider than median lobe in ventral view; apical emargination V-shaped, concave structure between parameres elongated narrow and deeply V-shaped with pointed end; narrowed gradually towards apical end, small bump near the apex in lateral view; gently curved on ventral side in lateral view; apex narrow oval and not overlap with median lobe, majority of parameres do not overlap median lobe with one space visible in lateral view.

\section{Female}

No morphological difference from male except for the $5^{\text {th }}$ longer abdominal ventrite. Ovipositor long, gonocoxites strongly tapering to a point.

\section{Morphological variation}

EL: $2.74-2.35 \mathrm{~mm}$, EW: $1.04-0.87 \mathrm{~mm}$, PL: $2.16-1.97 \mathrm{~mm}, \mathrm{PW}: 3.33-3.01 \mathrm{~mm}$.

\section{Distribution}

Caccothryptus championi sp. nov. is known only from the type locality.

Caccothryptus larryi sp. nov. urn:lsid:zoobank.org:act:C5571EBA-C47F-4375-AD03-7D11002761B1

Figs 4, 7D

\section{Diagnosis}

Caccothryptus larryi sp. nov. is within C. compactus group and can be distinguished by several genital characters: (1) apex of median lobe with two asymmetrical emarginations in ventral view; (2) concave structure between parameres an elongated narrow and deeply V-shaped with pointed end; (3) dorsal and ventral side of parameres smooth and elongate, narrowing towards apical end in lateral view; (4) apical emargination of parameres oval in ventral view. C. ripicola has semicircle shaped apical emargination of parameres, median lobe with symmetrical emarginations, overall genitalia long and thin, which differs significantly from C. larryi sp. nov.

\section{Etymology}

This species is named after 'Larry' the cat that lives at 10 Downing Street and the current 'Chief Mouser' to the Cabinet Office.

\section{Material examined}

Holotype

INDIA • O'; "AT LIGHT // Haldwani Divn. Kumaon, U.P. // 4017 // Caccothryptus ripicola Ch // Caccothryptus ripicola Champ. // H.G. Champion B.M. 1953-156 // NHMUK011225324”; BMNH.

\section{Paratype}

INDIA • 1 O; “AT LIGHT // Haldwani Divn. Kumaon, U.P. // 4017 // Caccothryptus ripicola Champ. // H.G. Champion B.M. 1953-156 // NHMUK011225325”; BMNH. 


\section{Description}

\section{Male}

Body. Elongate, oval, dorsum convex, EL: $2.44 \mathrm{~mm}$, EW: 2.09 mm, PL: $0.75 \mathrm{~mm}$, PW: $1.68 \mathrm{~mm}$. Colour: dorsal side brown; venter brown, tibia brown, tarsal claws light brown. Dorsal surface densely covered with long setae with patches of white setae forming a wavy pattern, ventral surface with relatively long setae.

Dorsum. Head: partially retracted into pronotum; overall surface smooth, densely punctured across surface. Antennae: 11 segmented, filiform, fully pubescent, antennomeres long and slender, $1^{\text {st }}$ AS widest, $2^{\text {nd }}$ AS narrow and long, $3^{\text {rd }}$ AS smallest, $4^{\text {th }}-11^{\text {th }}$ AS long, thin and obtusely angled on one side. Pronotum: transverse, widest at posterior end, narrowest at anterior end, narrower than elytra; anterior margin convex, posterior margin trisinuate, lateral margin convex; surface covered with dense punctation, surface between punctures smooth and shiny. Scutellum: subtriangular, large, lateral sides nearly straight. Elytra: longer than wide; anterior margin slightly convex, sinuate; anterior lateral angle

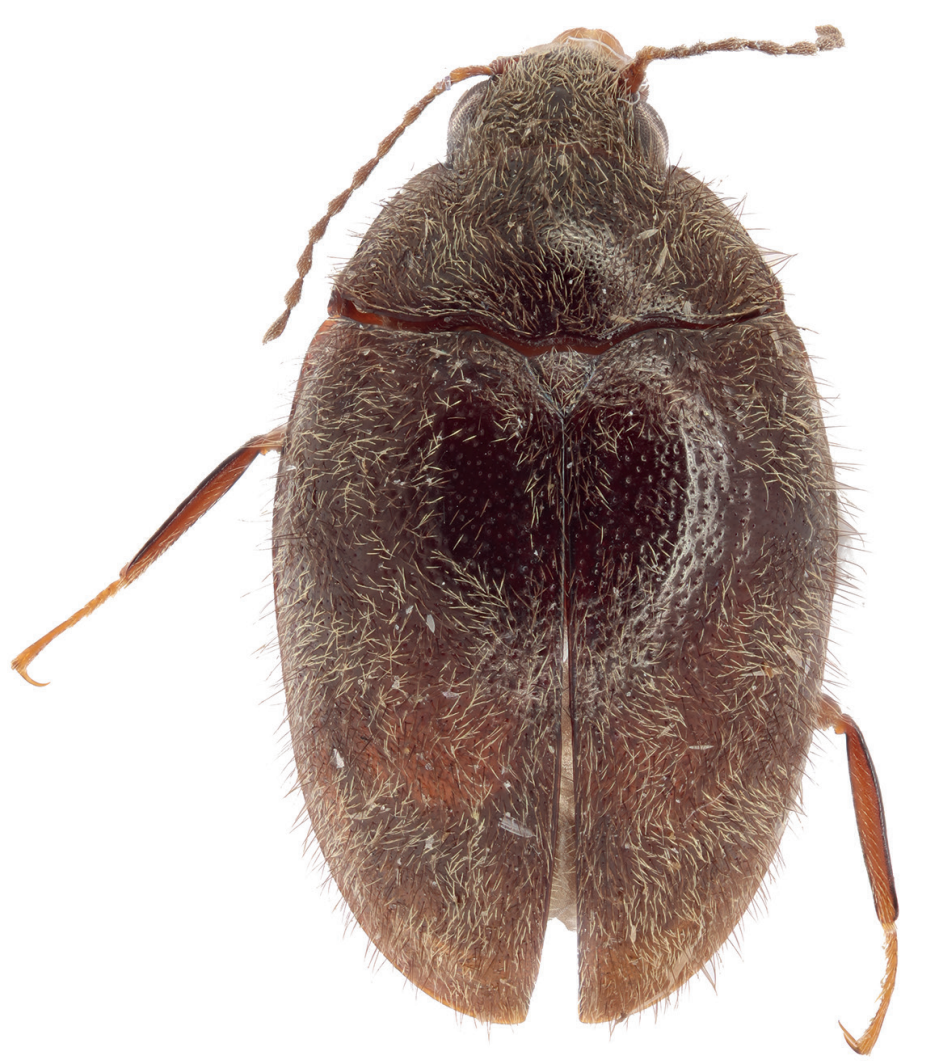

A

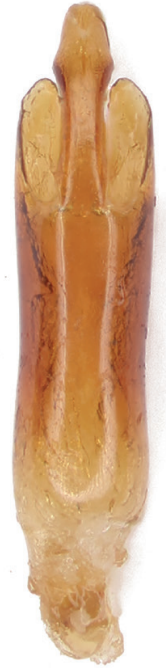

B

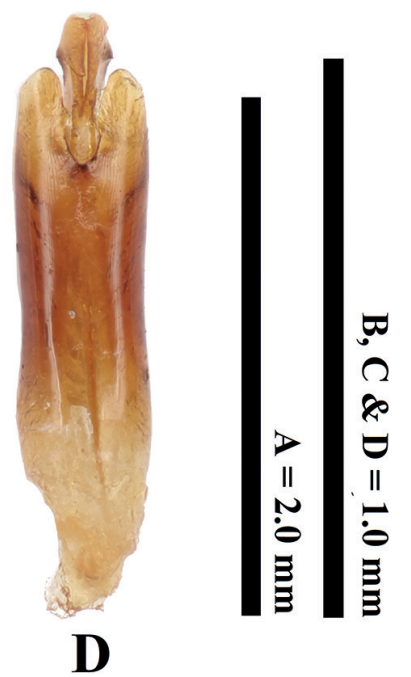

Fig. 4. Caccothryptus larryi sp. nov., Ô, holotype (NHMUK011225324). A. Dorsal habitus. B. Genitalia, dorsal. C. Genitalia, lateral. D. Genitalia, ventral. 
nearly right angled, pointed; lateral margins strongly bordered; surface with mixtures of small fine and medium sized punctuations; elytral striae not clearly visible throughout; surface between punctures smooth and shiny.

VENTER. Prosternum: concave on anterior margin, outer lateral margin concave; prosternal process as long as wide, lateral margin sinuated, posterior margin rounded. Mesoventrite: wider than long, narrowed towards posterior; anterior end concave where prosternal process fits, discrimen visible; laterally subparallel and gently curved, posteriorly flat, anteriorly trisinuate. Metaventrite: long and wide, flat on the middle; discrimen thin visible across each end. Abdomen: five clearly visible ventrites. Intercoxal process with pointed apex. Posterior margin of $1^{\text {st }}$ and $2^{\text {nd }}$ ventrites convex, $3^{\text {rd }}-4^{\text {th }}$ ventrites slightly concave around the middle, $5^{\text {th }}$ ventrite semioval. Surface covered with long, light yellow, recumbent setae.

LEGs. Tibia: protibia with narrowly oval. Meso- and metatibia with outer lateral margin almost straight, inner lateral margin straight. Tarsi: simple, segments increase in length towards the apex, $5^{\text {th }}$ tarsal segment as long as $1^{\text {st }}-4^{\text {th }}$ tarsal segment combined. Tarsal claws: Long, narrow, symmetrical.

GeNITALIA. Aedeagus: elongate, strongly sclerotised. Base: asymmetrical, width gently narrowed towards apical end. Median lobe: approximately $1 / 3$ length of genitalia; longer than parameres; consistent width on basal $2 / 3$, oval on apical half, maximum width of apical $1 / 3$ in lateral view; apex flat and edge rounded, lower half of lateral end gently concave in dorsal view; dorsal and ventral end curved, narrow near the apex, apex pointed, width relatively consistent in lateral view; triangular emarginate on one side towards parameres and small emarginate directing laterally in ventral view. Parameres: wider than median lobe in ventral view; apical emargination oval, concave structure between parameres an elongated U-shaped with rounded end; smooth and elongate, narrowed towards apical end, apex pointed and overlaps with median lobe, majority of parameres overlaps with median lobe with no visible spacing in lateral view.

\section{Female}

No morphological difference from male except for the longer $5^{\text {th }}$ abdominal ventrite. Ovipositor long, gonocoxites strongly tapering to a point. EL: $2.77 \mathrm{~mm}$, EW: $2.18 \mathrm{~mm}$, PL: $0.77 \mathrm{~mm}$, PW: $1.71 \mathrm{~mm}$.

\section{Distribution}

Caccothryptus larryi sp. nov. is known only from the type locality.

Caccothryptus tardarsauceae sp. nov. urn:1sid:zoobank.org:act:3DAF222E-1DF9-4254-BF38-627576985EA4

Figs 5, 7E

\section{Diagnosis}

Caccothryptus tardarsauceae sp. nov. is within the C. testudo group and can be distinguished by several genital characters: (1) apex of median lobe narrow with tip slightly pointed in ventral view; (2) concave structure between apical emargination narrowly V-shaped with gently pointed end; (3) dorsal side of parameres bisinuate in lateral view; (4) apical emargination of parameres V-shaped in ventral view.

\section{Etymology}

This species is named after the American internet celebrity cat 'Tardar Sauce', nicknamed 'Grumpy Cat'. 


\section{Material examined}

\section{Holotype}

INDIA • O’; "Jhatingri, Mandi. Punjab. 6,000ft. H.G.C. // H.G. Champion B.M. 1953-156 // NHMUK011225274"; BMNH.

\section{Description}

\section{Male}

Body. Elongate, oval, dorsum convex, EL: $3.64 \mathrm{~mm}$, EW: $2.50 \mathrm{~mm}$, PL: $0.87 \mathrm{~mm}$, PW: $2.11 \mathrm{~mm}$. Colour: dorsal side brown; venter brown, tibia reddish brown, tarsal claws light brown. Dorsal surface

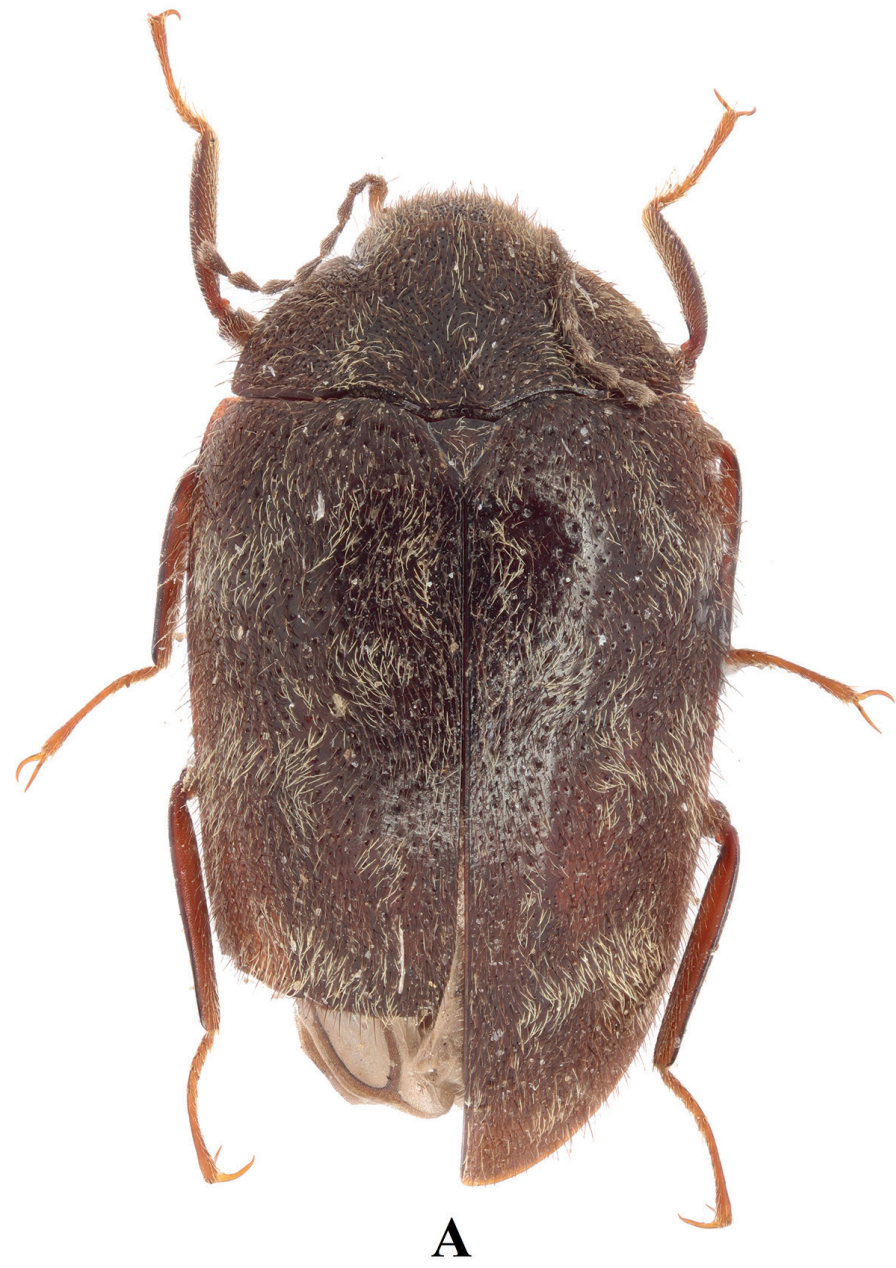

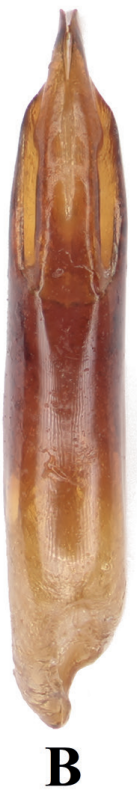

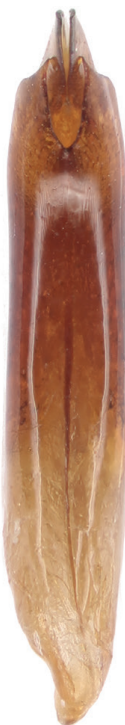

D

Fig. 5. Caccothryptus tardarsauceae sp. nov., Ô, holotype (NHMUK011225274). A. Dorsal habitus. B. Genitalia, dorsal. C. Genitalia, lateral. D. Genitalia, ventral. 
densely covered with long setae with patches of white setae forming a wavy pattern, ventral surface with relatively long setae.

DoRsum. Head: partially retracted into pronotum; overall surface smooth, densely punctured across surface. Antennae: 11 segmented, filiform, fully pubescent, antennomeres long and slender, $1^{\text {st }}$ AS widest, $2^{\text {nd }}$ AS narrow and long, $3^{\text {rd }}$ AS smallest, $4^{\text {th }}-11^{\text {th }}$ AS long, thin and obtusely angled on one side. Pronotum: transverse, widest at posterior end, narrowest at anterior end, narrower than elytra; anterior margin convex, posterior margin trisinuate, lateral margin convex; surface covered with dense punctation, surface between punctures smooth and shiny. Scutellum: subtriangular, large, lateral sides gently convex. Elytra: longer than wide; anterior margin slightly convex, sinuate; anterior lateral angle nearly right angled, pointed; lateral margins strongly bordered; surface with mixtures of small fine sized punctuations and medium sized punctuations forming irregular near the elytral suture; elytral striae more clearly visible towards lateral end; surface between punctures smooth and shiny.

Venter. Prosternum: concave on anterior margin, outer lateral margin concave; prosternal process as long as wide, lateral margin sinuated, posterior margin rounded. Mesoventrite: wider than long, narrowed towards posterior; anterior end concave where prosternal process fits, discrimen visible; laterally subparallel and gently curved, posteriorly flat, anteriorly trisinuate. Metaventrite: long and wide, flat on the middle; discrimen thin visible across each end. Abdomen: five clearly visible ventrites. Intercoxal process with pointed apex. Posterior margin of $1^{\text {st }}$ and $2^{\text {nd }}$ ventrites convex, $3^{\text {rd }}-4^{\text {th }}$ ventrites slightly concave around the middle, $5^{\text {th }}$ ventrite semioval. Surface covered with long, light yellow, recumbent setae.

Legs. Tibia: protibia with outer and inner lateral margin curved. Meso- and metatibia with outer lateral margin almost straight, inner lateral margin straight. Tarsi: simple, segments increase in length towards the apex, $5^{\text {th }}$ tarsal segment as long as $1^{\text {st }}-4^{\text {th }}$ tarsal segment combined. Tarsal claws: long, narrow, symmetrical.

GenITALIA. Aedeagus: elongate, strongly sclerotised. Base: asymmetrical, widest around basal 0.2 from both lateral and ventral view. Median lobe: approximately $1 / 3$ length of genitalia; longer than parameres; gently curved on dorsal side, slightly bisinuate on ventral side, widest at middle, narrowing towards the apex, apex with round point in lateral view; apex pointed, split into two on anterior half and edge pointed, lower half of lateral end relatively straight in dorsal view; apical end smooth and narrows inwards in ventral view. Parameres: wider than median lobe in ventral view; apical emargination wide V-shaped, concave structure between parameres elongated and wide V-shaped, with gently pointed end; bisinuate, lower half of sinuation long and shallow, upper half short and slightly deep on dorsal side in lateral view; gently curved on ventral side in lateral view; apex pointed and overlaps with median lobe, majority of parameres overlaps with median lobe in lateral view.

\section{Female}

Unknown.

\section{Distribution}

Caccothryptus tardarsauceae sp. nov. is known only from the type locality. 
Caccothryptus abboti sp. nov. urn:1sid:zoobank.org:act:42E7B7FB-5372-4F1E-9610-14F21C60406F

Figs $6,7 \mathrm{~F}$

\section{Diagnosis}

Caccothryptus abboti sp. nov. is within C. compactus group and can be distinguished by several genital characters: (1) apex of median lobe asymmetrical in ventral view; (2) concave structure between parameres deeply U-shaped with rounded end; (3) parameres deeply curved on dorsal side and gently curved on ventral side in lateral view; (4) apical emargination inward slanted and V-shaped.

\section{Etymology}

This species is named after Nick Abbot, who is a radio presenter.

\section{Material examined}

\section{Holotype}

INDIA • O'; "AT LIGHT // Haldwani Divn. Kumaon, U.P. // 4016 // 4016 // Caccothryptus testudo, Ch. // Caccothryptus testudo Champ. // H.G. Champion B.M. 1953-156 // NHMUK011225275"; BMNH.

\section{Description}

\section{Male}

Body. Elongate, oval, dorsum convex, EL: $3.21 \mathrm{~mm}$, EW: $2.62 \mathrm{~mm}$, PL: $1.01 \mathrm{~mm}$, PW: $2.05 \mathrm{~mm}$. Colour: dorsal side brown; venter brown, tibia reddish brown, tarsal claws light brown. Dorsal surface densely covered with long setae with patches of white setae forming a wavy pattern, ventral surface with relatively long setae.

Dorsum. Head: partially retracted into pronotum; overall surface smooth, densely punctured across surface. Antennae: 11 segmented, filiform, fully pubescent, antennomeres long and slender, $1^{\text {st }}$ AS widest, $2^{\text {nd }}$ AS narrow and long, $3^{\text {rd }}$ AS smallest, $4^{\text {th }}-11^{\text {th }}$ AS long, thin and obtusely angled on one side. Pronotum: transverse, widest at posterior end, narrowest at anterior end, narrower than elytra; anterior margin convex, posterior margin trisinuate, lateral margin convex; surface covered with dense punctation, surface between punctures smooth and shiny. Scutellum: subtriangular, large, lateral sides nearly straight. Elytra: longer than wide; anterior margin slightly convex, sinuate; anterior lateral angle acute, pointed; lateral margins strongly bordered; surface with mixtures of small fine and medium sized punctuations; elytral striae not clearly visible throughout; surface between punctures smooth and shiny.

VeNTER. Prosternum: concave on anterior margin, outer lateral margin concave; prosternal process as long as wide, lateral margin sinuated, posterior margin rounded. Mesoventrite: wider than long, narrowed towards posterior; anterior end concave where prosternal process fits, discrimen visible; laterally subparallel and gently curved, posteriorly flat, anteriorly trisinuate. Metaventrite: long and wide, flat on the middle; discrimen thin visible across each end. Abdomen: five clearly visible ventrites. Intercoxal process with pointed apex. Posterior margin of $1^{\text {st }}$ and $2^{\text {nd }}$ ventrites convex, $3^{\text {rd }}-4^{\text {th }}$ ventrites slightly concave around the middle, $5^{\text {th }}$ ventrite semioval. Surface covered with long, light yellow, recumbent setae.

Legs. Tibia: protibia with outer and inner lateral ends curved. Meso- and metatibia with outer lateral margin almost straight, inner lateral margin straight. Tarsi: simple, segments increase in length towards the apex, $5^{\text {th }}$ tarsal segment as long as $1^{\text {st }}-4^{\text {th }}$ tarsal segment combined. Tarsal claws: long, narrow, symmetrical. 
Genitalia. Aedeagus: elongate, strongly sclerotised. Base: asymmetrical, widest around basal 0.2 in ventral view, widest at middle in lateral view. Median lobe: approximately $2 / 5$ the length of genitalia; longer than parameres; curved on both dorsal and ventral side, consistent width, narrows near the apex, apex with rounded in lateral view; apex pointed, split into two on anterior $1 / 4$ and edge blunt, lower half of lateral end gently convex in dorsal view; apical end asymmetrical in ventral view. Parameres: wider than median lobe in ventral view; apical emargination inward slanted and V-shaped, concave structure between parameres deep U-shaped with rounded end; narrowed towards apical end, apical end oval in lateral view; deeply curved on dorsal side in lateral view; gently curved on ventral side in lateral view; apex narrow oval and overlaps with median lobe, majority of parameres overlaps with median lobe with no visible spacing in lateral view.

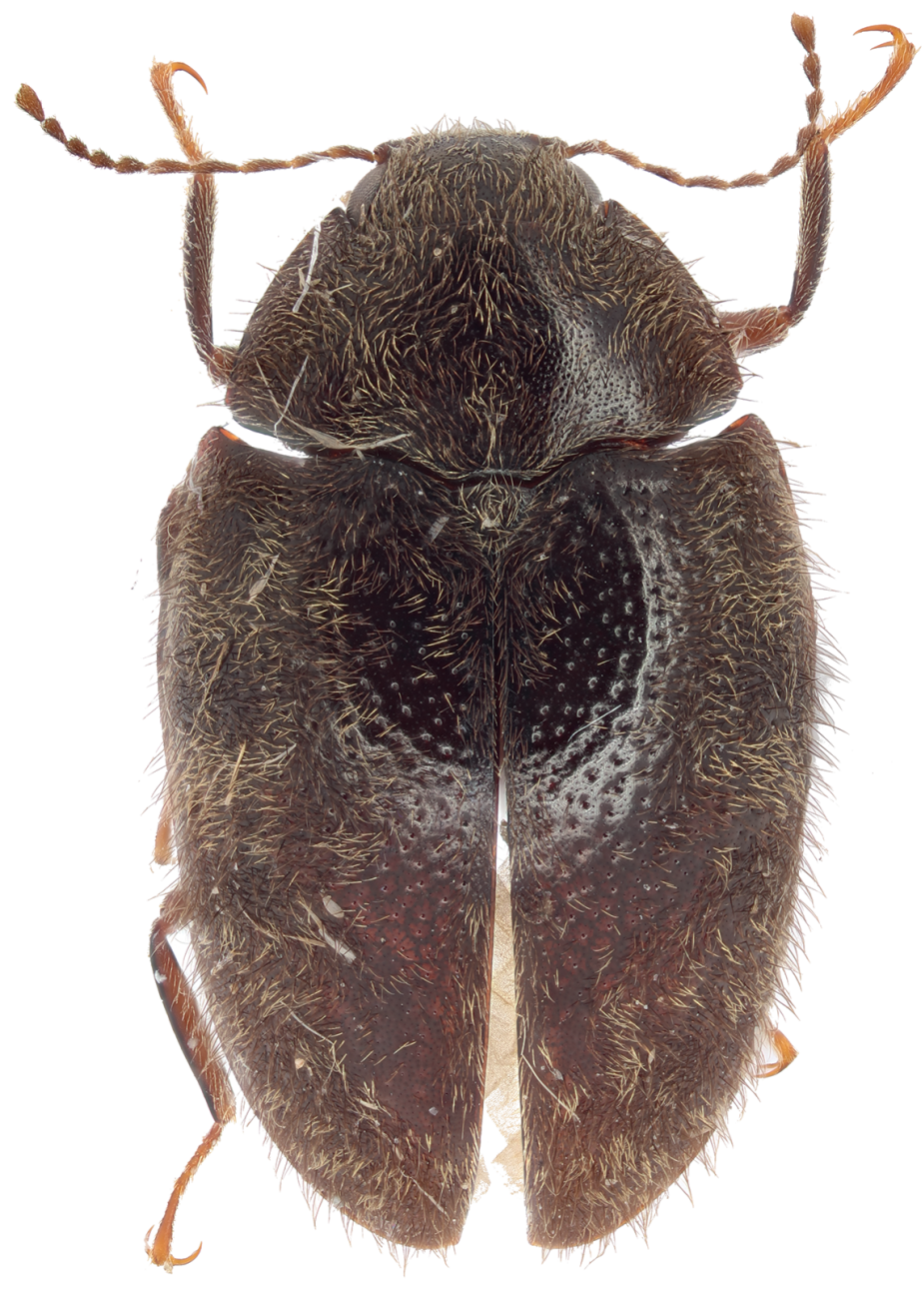

A
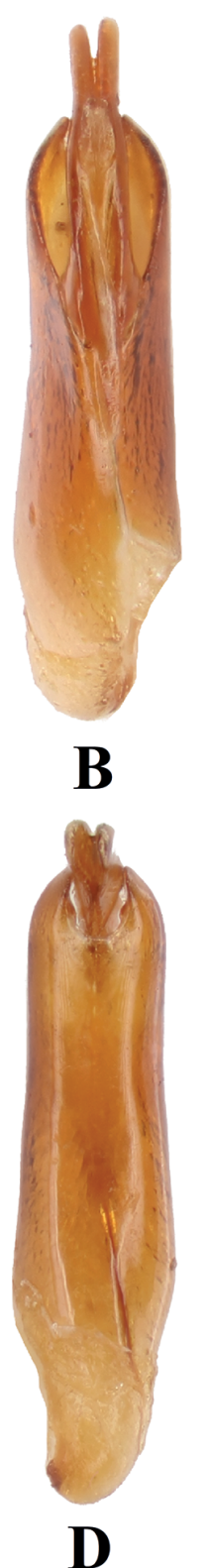
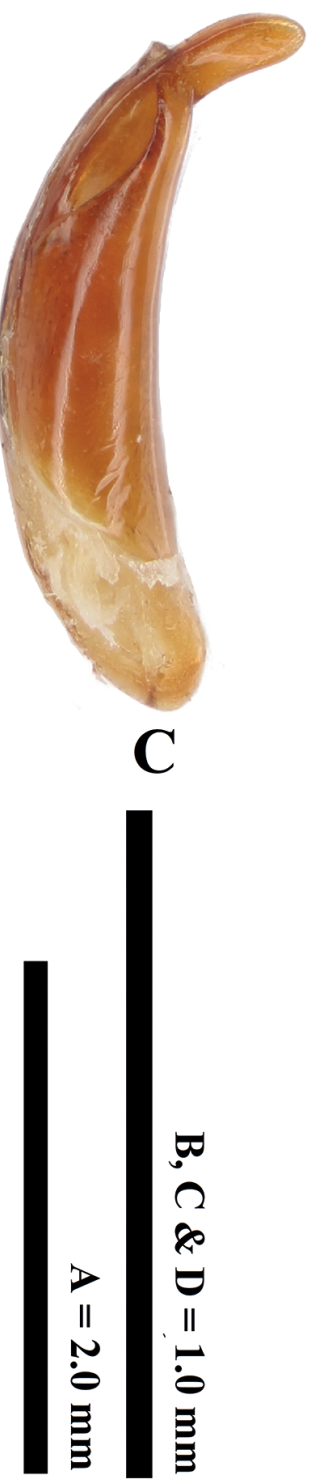

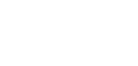

Fig. 6. Caccothryptus abboti sp. nov., §̂, holotype (NHMUK011225275). A. Dorsal habitus. B. Genitalia, dorsal. C. Genitalia, lateral. D. Genitalia, ventral. 
Female

Unknown.

\section{Distribution}

Caccothryptus abboti sp. nov. is known only from the type locality.

\section{Discussion}

There are now 12 species of Caccothryptus recorded from Himalaya region: C. brendelli sp. nov.; C. arakawae sp. nov.; C. championi sp. nov.; C. larryi sp. nov.; C. tardarsauceae sp. nov.; C. abboti

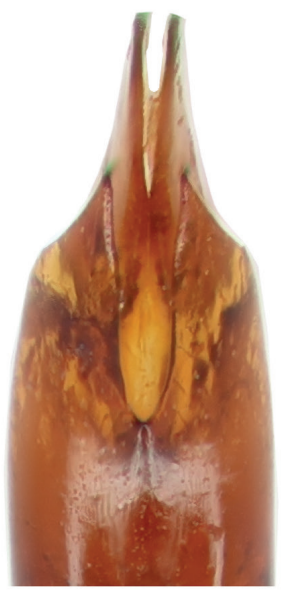

A

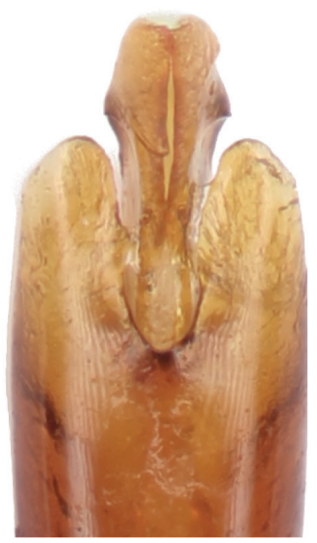

D

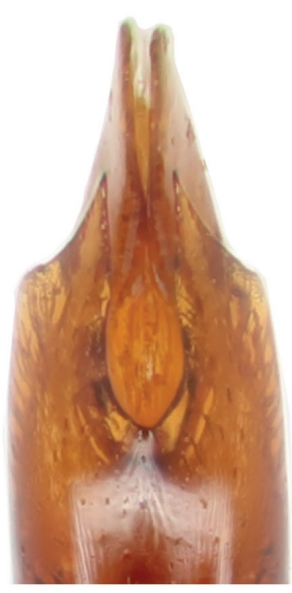

B

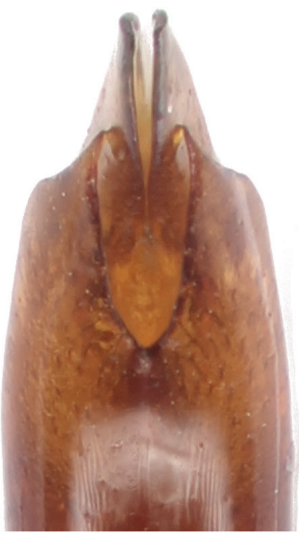

$\mathbf{E}$

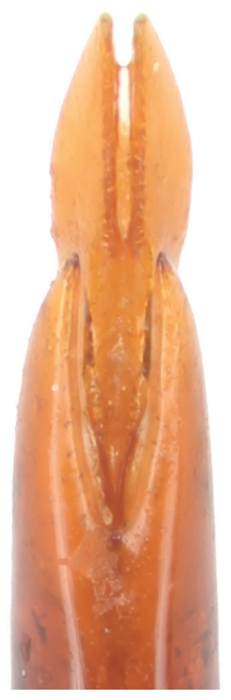

C

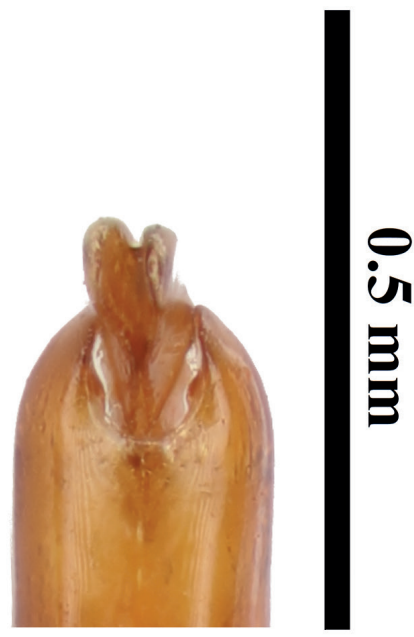

$\mathbf{F}$

Fig. 7. Close-up of Caccothryptus spp. genitalia ventral apex, $\widehat{O}$, holotype. A. C. brendelli sp. nov. (NHMUK011225276). B. C. arakawae sp. nov. (NHMUK011225268). C. C. championi sp. nov. (NHMUK011225382). D. C. larryi sp. nov. (NHMUK011225324). E. C. tardarsauceae sp. nov. (NHMUK011225274). F. C. abboti sp. nov. (NHMUK011225275). 
sp. nov.; C. jendeki Hernando \& Ribera, 2014; C. ripicola Champion, 1923; C. testudo Champion, 1923; C. occidentalis Hernando \& Ribera, 2017; C. tibetanus Yoshitomi, 2015; C. chayuensis Yoshitomi, 2015. This is the first time that species within the C. compactus group were represented within the Himalayan region.

\section{Acknowledgments}

I would like to thank Max Barclay (BMNH) providing access to the specimens studied. Many thanks to two anonymous reviewers for valuable and helpful comments on the manuscript.

\section{References}

Hernando C. \& Ribera I. 2014. Taxonomic revision of the genus Caccothryptus Sharp. Koleopterologische Rundschau 84: 281-304.

Hernando C. \& Ribera I. 2017. Three new species of the genus Caccothryptus Sharp, 1902 from Asia (Coleoptera: Limnichidae). Zootaxa 4243 (2): 366-370. https://doi.org/10.11646/zootaxa.4243.2.5

Spangler P.J., Staines C.L., Spangler P.M. \& Staines S.L. 2001. A checklist of the Limnichidae and the Lutrochidae (Coleoptera) of the world. Insecta Mundi 15 (3): 151-165.

Yoshitomi H. 2015. Four new species of the genus Caccothryptus (Coleoptera, Limnichidae). European Journal of Taxonomy 147: 1-7. https://doi.org/10.5852/ejt.2015.147

Yoshitomi H. 2018. A new species of the genus Caccothryptus (Coleoptera: Limnichidae) from China. Japanese Journal of Systematic Entomology 24 (1): 138-140.

Manuscript received: 29 July 2020

Manuscript accepted: 20 December 2020

Published on: 19 March 2021

Topic editor: Nesrine Akkari

Section editor: Max Barclay

Desk editor: Eva-Maria Levermann

Printed versions of all papers are also deposited in the libraries of the institutes that are members of the EJT consortium: Muséum national d'histoire naturelle, Paris, France; Meise Botanic Garden, Belgium; Royal Museum for Central Africa, Tervuren, Belgium; Royal Belgian Institute of Natural Sciences, Brussels, Belgium; Natural History Museum of Denmark, Copenhagen, Denmark; Naturalis Biodiversity Center, Leiden, the Netherlands; Museo Nacional de Ciencias Naturales-CSIC, Madrid, Spain; Real Jardín Botánico de Madrid CSIC, Spain; Zoological Research Museum Alexander Koenig, Bonn, Germany; National Museum, Prague, Czech Republic. 